\title{
Embryonic exposure to excess thyroid hormone causes thyrotrope cell death
}

\author{
Ksenia N. Tonyushkina, ${ }^{1,2}$ Meng-Chieh Shen, ${ }^{2}$ \\ Theresa Ortiz-Toro, ${ }^{1}$ and Rolf 0 . Karlstrom ${ }^{2}$
}

1Department of Pediatrics, Baystate Medical Center, Springfield, Massachusetts, USA.

2Department of Biology, University of Massachusetts, Amherst, Massachusetts, USA.

\begin{abstract}
Central congenital hypothyroidism (CCH) is more prevalent in children born to women with hyperthyroidism during pregnancy, suggesting a role for thyroid hormone (TH) in the development of central thyroid regulation. Using the zebrafish embryo as a model for thyroid axis development, we have characterized the ontogeny of negative feedback regulation of thyrotrope function and examined the effect of excess TH on thyrotrope development. We found that thyroid-stimulating hormone $\beta$ subunit (tshb) and type 2 deiodinase (dio2) are coexpressed in zebrafish thyrotropes by 48 hours after fertilization and that TH-driven negative feedback regulation of $t s b b$ transcription appears in the thyroid axis by 96 hours after fertilization. Negative feedback regulation correlated with increased systemic TH levels from the developing thyroid follicles. We used a transgenic zebrafish that expresses GFP under the control of the $t s b b$ promoter to follow thyrotrope fates in vivo. Time-lapse imaging revealed that early exposure to elevated TH leads to thyrotrope cell death. Thyrotrope numbers slowly recovered following the removal of excess TH. These data demonstrate that transient TH exposure profoundly impacts the thyrotrope population during a critical period of pituitary development and may have long-term implications for the functional reserve of thyroid-stimulating hormone (TSH) production and the TSH set point later in life.
\end{abstract}

\section{Introduction}

Thyroid hormone (TH) is essential for normal development of the brain, liver, heart, intestine, blood, and bone both before (1-4) and after birth (5). Congenital hypothyroidism $(\mathrm{CH})$ is an important cause of developmental deficits (6) and an increasingly common problem in the neonatal population (7). Approximately $80 \%$ of $\mathrm{CH}$ cases can be attributed to thyroid gland dysgenesis, while it is estimated that $5 \%-10 \%$ of cases are due to thyroid enzymatic defects, $2 \%-5 \%$ are caused by maternal autoimmunity, and the remaining $5 \%$ of cases are defined by improper central regulation of $\mathrm{TH}$ production by the hypothalamus and pituitary gland (8). This central $\mathrm{CH}(\mathrm{CCH})$ could either result from defects in the hypothalamic control of thyroid-stimulating hormone (TSH) production or from defects in the number and/or function of thyrotropes within the pituitary gland itself. Both transient and permanent $\mathrm{CCH}$ are estimated to occur in 1 of 70 infants born to mothers with hyperthyroidism due to poorly controlled Graves' disease (9). Animal models of autoimmunity-independent maternal hyperthyroxinemia, DIO3 (10) and TH receptor $\beta$ (11) mouse knockouts showed variable dysregulation within the thyroid axis that persisted postembryonically. This suggests that maternal TH levels affect the development of the hypothalamic-pituitary unit and could have important clinical consequences over the human lifespan.

The mechanisms underlying $\mathrm{CCH}$ in infants remain unclear but could be related to defects in the development of negative feedback at multiple points within the hypothalamic/pituitary/ thyroid (HPT) axis, including thyrotrope differentiation within the developing pituitary. Surprisingly little is known about the ontogeny and functional maturation of thyrotropes during early embryogenesis. The zebrafish embryo provides a powerful genetic

Conflict of interest: The authors have declared that no conflict of interest exists. Citation for this article: J Clin Invest. 2014;124(1):321-327. doi:10.1172/JCI70038 and experimental model for these studies, as pituitary and thyroid functions are highly conserved across vertebrate species (12-14). In zebrafish, TH is supplied by the yolk sac from the beginning of embryogenesis (15). Thyroid follicles (the analog of the human thyroid gland) first produce $\mathrm{T} 4$ by 3 days post fertilization (dpf) (16), and substantial changes in tissue levels of T4 first occur by $5 \mathrm{dpf}$ (17). TRH-producing cells are widely distributed in the zebrafish brain, including in the diencephalon, where thyrotropin-releasing hormone-containing (TRH-containing) fibers project to the adenohypophysis (18). Importantly, hormone levels can be easily manipulated in the zebrafish embryo, and thyrotropes can be tracked in real time, facilitating the analysis of HPT axis development under hyperthyroid conditions.

Here, we report the impact of excess TH on early thyrotrope development and define the onset of negative regulation of TSH transcription by TH in thyrotropes. To image thyrotropes in live embryos, we generated a zebrafish transgenic line in which the GFP was inserted into the genome under tshb promoter regulation. Unexpectedly, we found that elevated TH levels trigger thyrotrope cell death before - but not after - the onset of negative feedback regulation of tshb expression. These studies identify an important developmental window of TH action and uncover thyrotrope cell death as a potential mechanism underlying $\mathrm{CCH}$ and altered set points in mammalian neonates exposed to high levels of maternal TH during embryogenesis, as occurs in poorly controlled Graves' disease in humans (9) and in Dio3-and $\operatorname{TR} \beta$-deficient mice $(10,11)$.

\section{Results}

Early thyrotrope differentiation in the zebrafish pituitary placode. To determine when thyrotropes first appear during embryogenesis and to examine the ontogeny of negative feedback regulation of $t s h b$ gene expression, we carefully documented the appearance of 


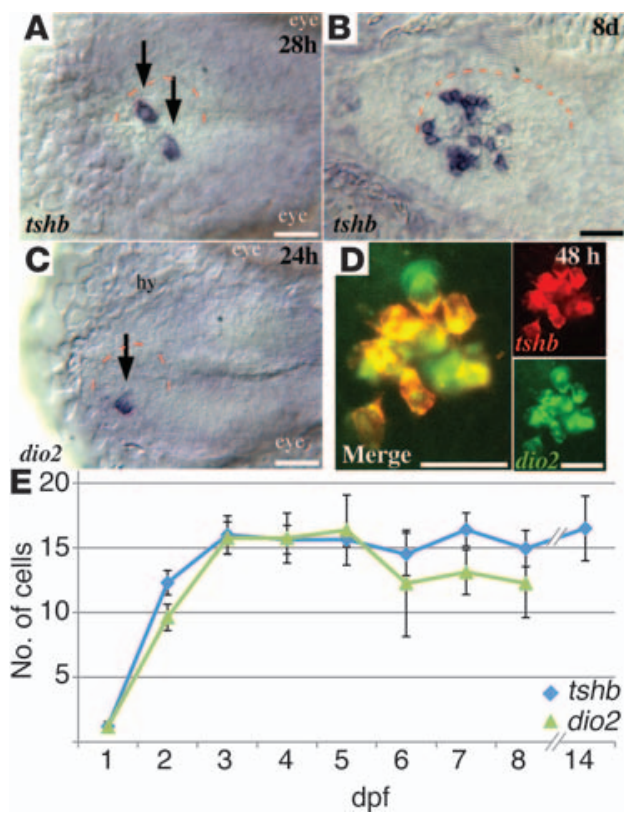

\section{Figure 1}

Thyrotrope differentiation through zebrafish embryonic and early larval stages. (A) tshb was first expressed between 28 and $32 \mathrm{hpf}$ in 1 to 2 cells of the pituitary placode as revealed by ISH. (B) Thyrotrope numbers increased to approximately 12 cells by $8 \mathrm{dpf}$. (C) dio2 is first expressed in 1 to 2 pituitary cells by $24 \mathrm{hpf}$, approximately 4 hours before tshb expression begins. (D) Double-fluorescence ISH revealed that tshb and dio2 were coexpressed in thyrotropes by $48 \mathrm{hpf}$. (E) Graph showing increases in thyrotrope cell numbers over the first 14 days of development, as determined by counting tshb- (blue) and dio2-expressing (green) cells. (A-D) Ventral views of the left anterior head between the eyes; dashed red lines outline the left half of the pituitary placode, which is positioned ventral to the hypothalamus (hy). Scale bars: $25 \mu \mathrm{m}$.

thyrotropes through embryonic and early larval stages based on expression of $t s h b$ and iodothyronine deiodinase 2 (dio2), which is required for the conversion of $\mathrm{T} 4$ to the more potent $\mathrm{T} 3 \mathrm{form}$. The expression of zebrafish $t s h b(19,20)$ was first seen in 1 to 2 thyrotropes in the developing pituitary placode starting as early as 28 hours post fertilization (hpf), with thyrotropes increasing to approximately 12 cells by $8 \mathrm{dpf}$ (Figure 1, A and B). dio 2 expression (21) began approximately 4 hours earlier than that of $t s h b$ in the early pituitary placode (Figure $1 \mathrm{C}$ ), and tshb and dio 2 were coexpressed in early thyrotropes from the time tshb expression began (Figure 1D). All cells in the pituitary expressing dio 2 also expressed $t s h b$. However, the reverse was not true, with approximately $10 \%$ of the tshb-expressing cells having no detectable dio 2 expression. Thyrotrope numbers increased steadily from 2 to 5 days, then remained essentially unchanged through early larval development up to $14 \mathrm{dpf}$ (Figure 1E), despite marked increases in other endocrine cell types (data not shown).

Early embryonic exposure to elevated T4 levels leads to thyrotrope cell death. Early expression of the TH-processing enzyme Dio 2 in the anterior pituitary (Figure 1C) is consistent with a role for thyroid hormone in pituitary development and/or function. To determine whether thyrotropes can respond to altered TH levels early in development, we examined tshb expression in the presence of elevated TH levels. Exposure to 100 or 300 nM T4 between 24 and
$48 \mathrm{hpfled}$ to a dramatic reduction in the number of pituitary cells expressing both tshb and dio2 (Figure 2, A-E). Similar reductions in $t s h b$ and dio 2 gene expression were seen when thyrotropes were exposed to TH between 48 and 72 hpf (Figure 2, F-H). T3 exposure similarly reduced tshb-expressing cell numbers in a dose-dependent manner (Figure 2H). This effect of TH appeared specific, as other pituitary endocrine cell types including lactotropes and somatotropes were not affected, even after 48 hours of exposure to elevated TH (Figure 2I).

The observed decreases in tshb-expressing cells (as assayed by in situ hybridization [ISH]) could be due to the suppression of tshb mRNA production (negative feedback on gene transcription) within thyrotropes, or to the loss of thyrotropes themselves. To follow thyrotrope cell fates, we developed a new transgenic zebrafish line that expresses the GFP protein under the control of the tshb promoter element (Figure 3A). We exposed 48-hpf $\mathrm{Tg}(t s h b: E G F P)$ transgenic embryos to T4 and observed thyrotropes using timelapse microscopy (Figure 3, B-L and Supplemental Video 1; supplemental material available online with this article; doi:10.1172/ JCI70038DS1). The GFP protein is stable in live cells for 24 to 48 hours $(22,23)$, which allowed us to track thyrotropes even if tshb gene transcription was reduced. Surprisingly, GFP-labeled thyrotropes rapidly disappeared starting 6-8 hours after the addition of $300 \mathrm{nM}$ T4 (Figure 3F and Supplemental Video 1). Fourteen hours after T4 addition, thyrotrope numbers were reduced to 2 to 3 cells (Figure $3 \mathrm{~L}$ ). Before disappearing, thyrotropes were seen to bleb and fragment, consistent with programmed cell death (PCD). To confirm that $\mathrm{T} 4$ treatment led to thyrotrope cell death, we labeled $\mathrm{Tg}(t s h b: E G F P)$ embryos with an antibody that recognizes the activated caspase 3 protein (24) 6, 8, 10, and 12 hours after the addition of T4. At each of these time points, 1-3 GFP-labeled thyrotropes were labeled with the activated caspase 3 antibody (Figure 3 , $\mathrm{M}-\mathrm{O})$, consistent with PCD.

Thyrotrope recovery following early T4-induced cell death. To determine whether early exposure to elevated TH levels could have lasting effects on the thyrotrope population, we next examined whether thyrotrope numbers recover following a 24-hour pulse of T4. $\mathrm{Tg}(t s h b: E G F P)$ embryos were exposed to $300 \mathrm{nM}$ T4 from 48 to $72 \mathrm{hpf}$, followed by an 11- or 15-day chase period in which embryos experienced normal rearing conditions. Thyrotrope numbers were drastically reduced 24 hours after T4 application (Figure 4, A and B), consistent with the experiments described above (Figures 2 and 3). Following the 11-day chase period, the thyrotrope population continued to be reduced by approximately 66\% (Figure 4, C, D, and G). Thyrotrope numbers returned to normal after a 15 -day chase period (Figure 4, E-G).

Onset of TH negative feedback on tshb transcription. The dramatic cell death associated with early $\mathrm{T} 4$ exposure led us to investigate when during development elevated T4 levels cease to be toxic to thyrotropes and instead cause thyrotropes to downregulate tshb gene expression. As shown in Figure 3, the tshb:EGFP line allowed us to track GFP fluorescence in thyrotropes, even when reduced tshb transcription made them undetectable by ISH. In 2-dpf embryos, exposure to $30 \mathrm{nM}$ T4 had no significant effect on the number of cells expressing tshb mRNA and did not significantly affect thyrotrope cell numbers overall (Figure 5A). Exposure to 100 and $300 \mathrm{nM}$ T4 caused cell death in a dose-dependent manner (Figure 5A). In contrast, by $4 \mathrm{dpf}, 30 \mathrm{nM}$ T4 exposure reduced the number of $t s h b$-expressing cells by greater than $50 \%$ as assayed by ISH, while only slightly reducing thyrotrope numbers as assayed 
by GFP expression (Figure 5B). Exposure to $100 \mathrm{nM}$ and $300 \mathrm{nM}$ $\mathrm{T} 4$ at this stage continued to result in significant thyrotrope cell death (Figure 5B). In 7-dpf larvae (Figure 5C), T4 exposure was no longer toxic to thyrotropes, even at the highest doses (300 nM). At this time, even low doses of T4 $(30 \mathrm{nM})$ reduced tshb gene expression in most cells of the pituitary. Thus by $7 \mathrm{dpf}$, even high doses of $\mathrm{T} 4$ ceased to be toxic, and larval thyrotropes responded to low doses of $\mathrm{T} 4$ exposure by reducing tshb gene expression. This indicates that appropriate negative feedback regulation of TH on tshb gene transcription begins to be established by $4 \mathrm{dpf}$ and is fully established by $7 \mathrm{dpf}$ (Figure 5C).

One possible explanation for the loss of $\mathrm{T} 4$ toxicity at later developmental stages could be an increase in the activity of the deactivating enzyme Dio3, which converts T4 and T3 into the inactive forms reverse T3 (rT3) and T2. To begin to test this hypothesis, we first used reverse transcription quantitative PCR (RT-qPCR) to analyze the baseline expression levels of dio 3 in the larvae heads $3 \mathrm{dpf}$ and $8 \mathrm{dpf}$ and found that dio 3 expression increased approximately 8 -fold between days 3 and 8 in the untreated fish. We then analyzed dio 3 expression following a 24-hour T4 exposure $3 \mathrm{dpf}$ and $8 \mathrm{dpf}$. In the absence of exogenous $\mathrm{TH}$, dio 3 was not detectable in the brain by ISH at either time point (Figure 5D). Following T4 exposure, dio 3 mRNA levels were regionally increased in the ventral diencephalon, dorsal to the pituitary gland (Figure 5E). TH exposure led to 15- and 20-fold increases in dio3 expression levels by RT-qPCR on days 3 and 8, respectively. We next normalized dio3 mRNA levels following $\mathrm{TH} /$ control exposure $8 \mathrm{dpf}$ to expression levels in control 3-day-old larvae (Figure 5F). Given the higher baseline expression of dio 3 by $8 \mathrm{dpf}$, TH-mediated dio 3 induction resulted in an approximately 6-fold increase in dio3 levels $8 \mathrm{dpf}$ relative to those observed $3 \mathrm{dpf}$.

\section{Discussion}

Ontogeny of central thyroid feedback regulation. These studies document early thyrotrope development and the onset of the negative feedback control of tshb gene expression in the zebrafish, an emerging model for the study of developing vertebrate hormone systems. Thyrotropes were first identified $48 \mathrm{hpf}$ based on expression of the tshb gene $(19,20)$, with dio 2 expression being shown $24 \mathrm{hpf}$ (21). Here, we show that thyrotropes first differentiate 20-24 hpf based on the expression of dio2, followed within hours by the expression of $t s h b$ (Figure 1). We found zebrafish dio2 to be expressed in thyrotropes themselves (Figure 1), as in rodents (25), but distinct from humans, in whom dio2 is expressed in a particular subset of folliculostellate cells that are proposed to modulate anterior pituitary hormone secretion (26). Dio 2 converts T4 to the more potent T3, thus early coexpression suggested that thyrotropes may be born with the ability to functionally respond to TH. However, we found that negative feedback regulation of tshb transcription by T 4 did not emerge until approximately 5 to $7 \mathrm{dpf}$, roughly coinciding with increased T4 tissue levels that result from maturation of the thyroid follicles (17). Feedback regulation within the HPT axis would be unnecessary before this time, since maternal deposition of TH in the yolk (27) cannot be regulated by the embryo. This is similar to the situation in humans, where maternal $\mathrm{TH}$ is the major source for the fetus until the second trimester of development, with $\mathrm{TH}$ signaling in the embryo being regulated by deiodinases as well as by $\mathrm{TH}$ transporter and $\mathrm{TH}$ receptor isoforms in embryonic membranes, cavities, and tissues (28).

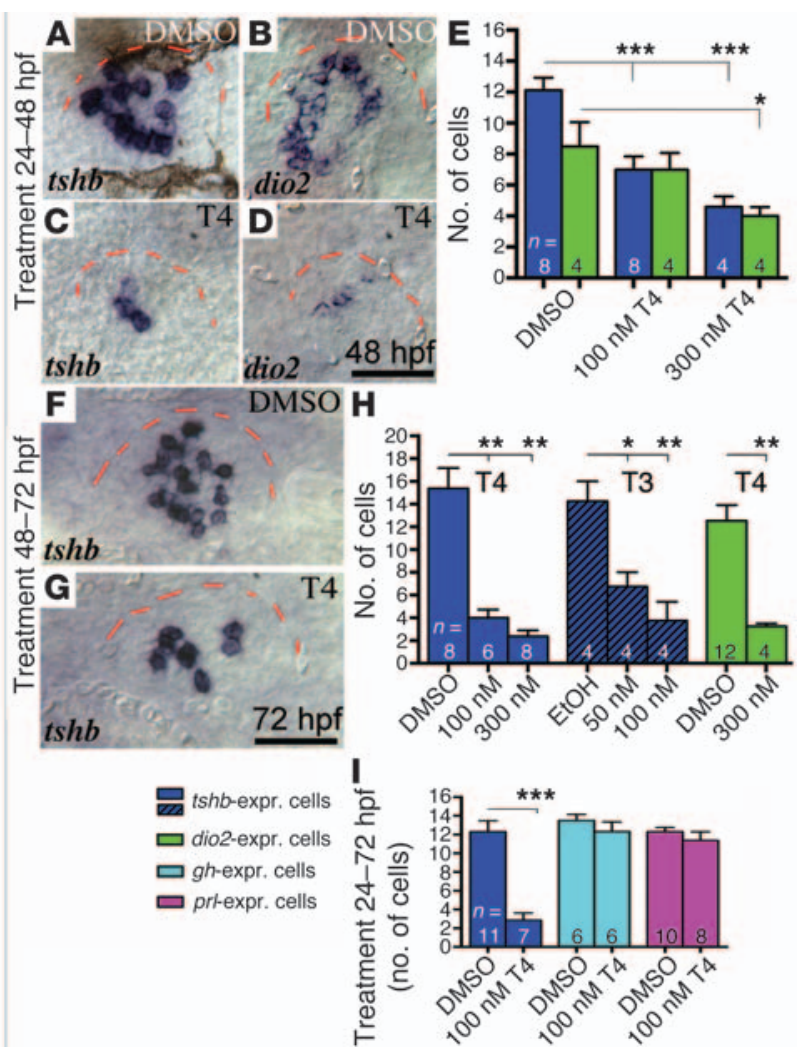

\section{Figure 2}

Embryonic exposure to elevated T4 reduces the number of cells expressing tshb and dio2. (A-D) tshb- and dio2-expressing thyrotropes by $48 \mathrm{hpf}$ following exposure to $300 \mathrm{nM} \mathrm{T4}$ or DMSO (carrier) starting at $24 \mathrm{hpf}$, as visualized by ISH. (E) Graph showing decreases in tshb- (blue) and dio2-labeled (green) cells. (F and $\mathbf{G}$ ) tshb-expressing thyrotropes by $72 \mathrm{hpf}$ following a 24-hour exposure to $300 \mathrm{nM} \mathrm{T4}$ or DMSO. (H) Graph showing decreases in tshb- (blue) and dio2-labeled (green) cells after a 24-hour exposure to T4 and T3. (I) Graph showing a decrease in tshb-labeled (blue) cells and no changes in $g h$ - and prl-labeled cells after a 48-hour exposure to $100 \mathrm{nM} \mathrm{T4}$ or DMSO (carrier) started 24 hpf. ${ }^{*} P<0.05 ;{ }^{* \star} P<0.01 ;{ }^{* \star \star} P<0.001$. (A-D, F, and G) Ventral views of the left anterior head; red dashed lines outline the left half of the pituitary placode. Scale bars: $25 \mu \mathrm{m}$.

Early exposure to elevated TH levels leads to thyrotrope cell death. Before approximately $5 \mathrm{dpf}$, elevated levels of T4 resulted in thyrotrope-specific cell death in the pituitary. This cell death occurred via a PCD pathway as indicated by characteristic changes in cellular morphology as well as the expression of the activated caspase 3 protein in dying thyrotropes (Figure 3 and Supplemental Video 1). Selective TH-induced cell death has been well studied in amphibian metamorphosis, where a surge of $\mathrm{TH}$ acting through $\mathrm{TH}$ receptor $\beta(\operatorname{Tr} \beta)$ transcriptionally activates apoptosis-related genes in some tissues (29). Our data reveal temporal changes in the $\mathrm{TH}$ response within thyrotropes, with TH exposure leading to cell death only prior to $7 \mathrm{dpf}$. After $7 \mathrm{dpf}$, TH exposure resulted in the normal downregulation of $t$ shb gene expression.

The mechanisms underlying selective TH induction of PCD pathways remain poorly understood. We wondered whether temporally distinct responses to $\mathrm{TH}$ could result from changes in deiodinase enzyme levels at later stages that would serve to inac- 


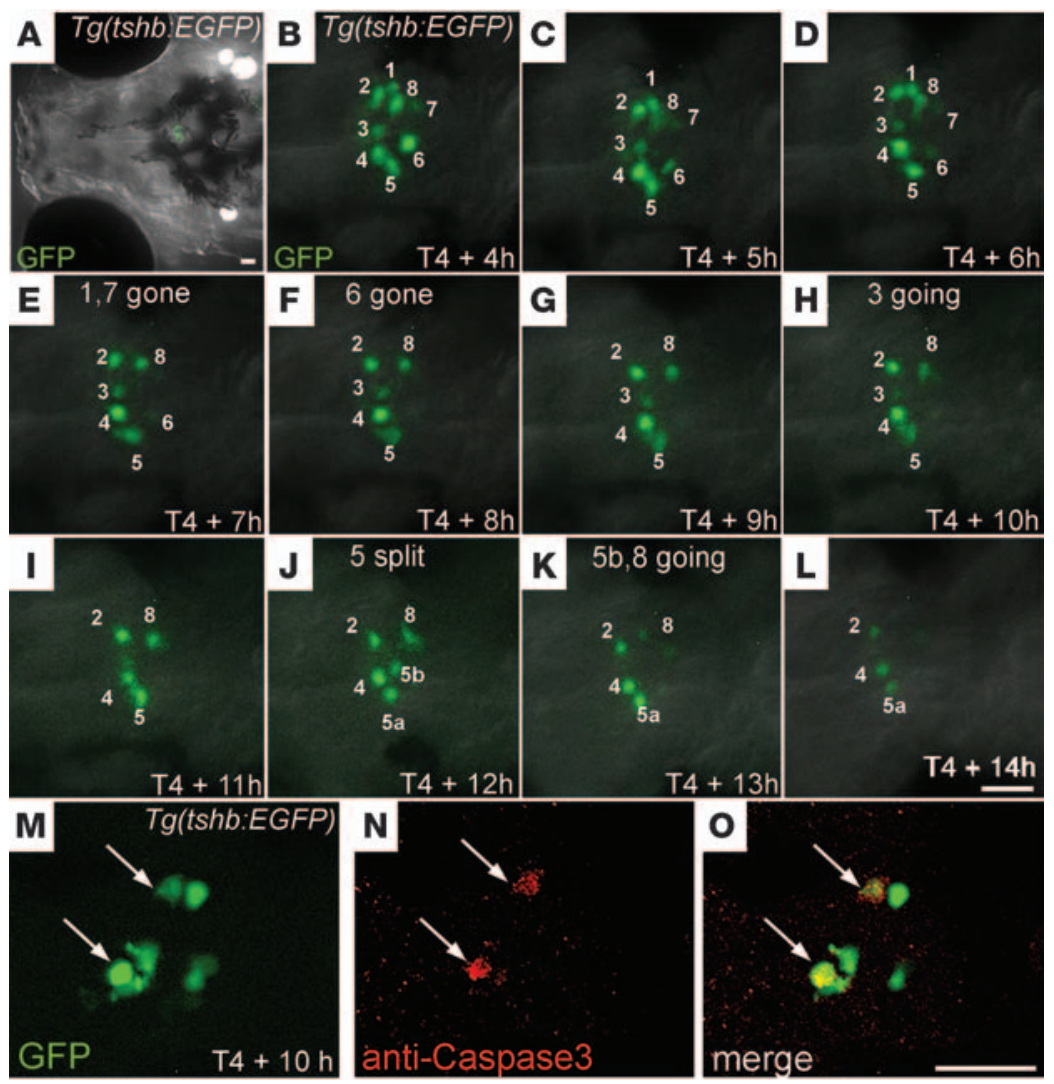

\section{Figure 3}

Early embryonic exposure to high T4 levels leads to thyrotrope cell death. (A) Ventral view of the zebrafish head in a 6-dpf $T g$ (tshb:EGFP) embryo showing GFP-labeled thyrotropes in the pituitary. (B-L) Single frames from a time-lapse movie (see Supplemental Video 1) of GFP-expressing thyrotropes (numbered) in a $T g$ (tshb:EGFP) embryo 4-14 hours after the application of 300 nM T4 48 hpf. (B) Eight GFP-expressing thyrotropes were present 4 hours after application of T4. (D and E) GFP-expressing thyrotropes began to disappear 6-7 hours after T4 application. (L) Only 3 cells remained 14 hours after application of T4. (M-O) Example of anti-activated caspase 3 labeling of 2 GFPexpressing thyrotropes (arrows) in a $T g$ (tshb:EGFP) embryo 10 hours after the application of $300 \mathrm{nM} \mathrm{T4}$. Single focal plane images show GFP (M), caspase 3 $(\mathbf{N})$, and merged channels ( $\mathbf{O})$. All panels show ventral views of the left anterior forebrain between the eyes. Scale bars: $25 \mu \mathrm{m}$ tivate excess hormone. We found that dio 3 was induced by $\mathrm{T} 4$ at both early and late larval stages, but that overall dio3 levels were significantly higher by $8 \mathrm{dpf}$ (Figure $5 \mathrm{~F}$ ), consistent with a protective effect that could keep TH levels below a threshold needed to trigger PCD pathways. Other factors contributing to a changing response to $\mathrm{TH}$ could include the altered expression of TH-binding proteins, transporters, and transcriptional cofactors. The temporally changing response to $\mathrm{TH}$ in the zebrafish pituitary gland provides a new model for understanding the mechanisms underlying altered cellular responses to elevated $\mathrm{TH}$.

Consequences of developmental exposure to elevated TH. Clinical observations and rodent studies revealed that hyperthyroxinemia during development can result in a spectrum of immediate and extended hypothalamic-pituitary abnormalities in the thyroid axis, ranging from profound central hypothyroidism to alterations in TSH sensitivity to TH input or alterations of the TSH set point. These studies used a number of challenge approaches (TRH stimulation tests, exposure to goitrogens, or $\mathrm{TH}$ exposure) to examine the regulatory capacity within the thyroid axis $(9-11,30)$. While the mechanisms remain poorly understood, these reports clearly link altered hypothalamic-pituitary regulation or set point to developmental hyperthyroxinemia $(11,30)$. In humans, transient $\mathrm{CCH}$ is now a well-established phenomenon in infants exposed to maternal hyperthyroxinemia due to poorly controlled Graves' disease $(9,31)$. Consistently, mouse embryos that lack Dio3 experience high levels of TH throughout development (10). While Dio3-deficient mice are viable, they display central hypothyroidism that persists into adulthood (10). Similarly, the administration of TH to neonatal rats results in central hypothyroidism, as indicated by an impaired pituitary response to TRH and an altered TSH set point/hypothalamic-pituitary response to $\mathrm{TH}$ (30). Thyrotrope resistance to a TH negative feedback also persists into adulthood in the offspring of TH receptor $\beta$ knockout dams due to the hyperthyroxinemic environment experienced by the embryo in utero. Our findings of thyrotrope cell death following $\mathrm{TH}$ exposure in zebrafish suggest a possible mechanism for the $\mathrm{CCH}$ or abnormal thyrotrope set point observed in the studies outlined above.

Zebrafish larval developmental stage starts at approximately $3 \mathrm{dpf}$, when embryos hatch from a chorion and become free-swimming and ends by approximately 3 to 4 weeks after fertilization, when metamorphosis to the adult form occurs (32). Thyrotrope numbers remained low 11 days after a 24-hour pulse of $\mathrm{TH}$ exposure, but were normal after 15 days. This period of recovery represents a developmental window of $20 \%$ to $25 \%$ of larval development in which altered TSH levels could lead to a compromised HPT axis. Hypothyroidism experienced during the recovery period would likely have consequences for other developing tissues, including the thyroid gland itself (33), that could persist into adulthood. In a study of $\mathrm{CCH}$ cases that resulted from maternal hyperthyroxinemia in Graves' disease, $\mathrm{CCH}$ was transient, but patients were found to have subtle thyroid abnormalities that manifested as primary hypothyroidism (34). Our finding that zebrafish thyrotrope numbers recovered when excess T4 was removed may help explain the transience of $\mathrm{CCH}$ in infants born to hyperthyroid mothers (9).

In summary, we have established the timing of thyrotrope differentiation and the onset of negative feedback regulation in the 


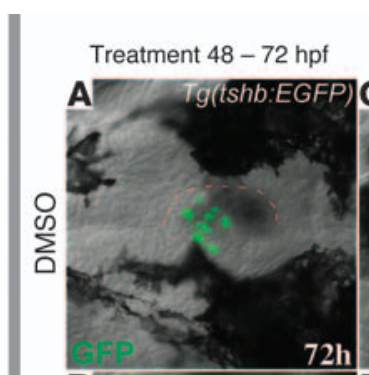

Treatment $48-72$ hpf Washout 11 days

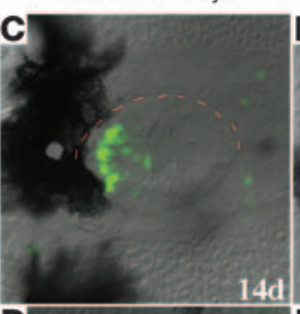

Treatment $48-72 \mathrm{hpf}$ Washout 15 days

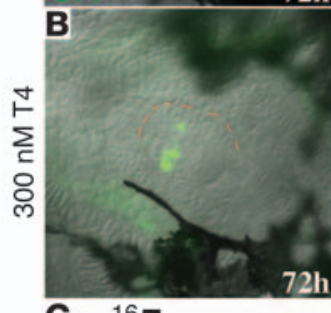

E

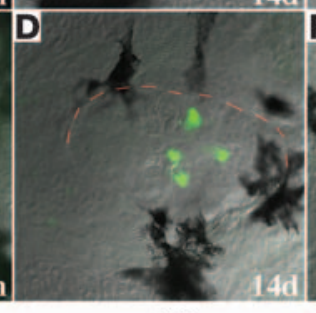

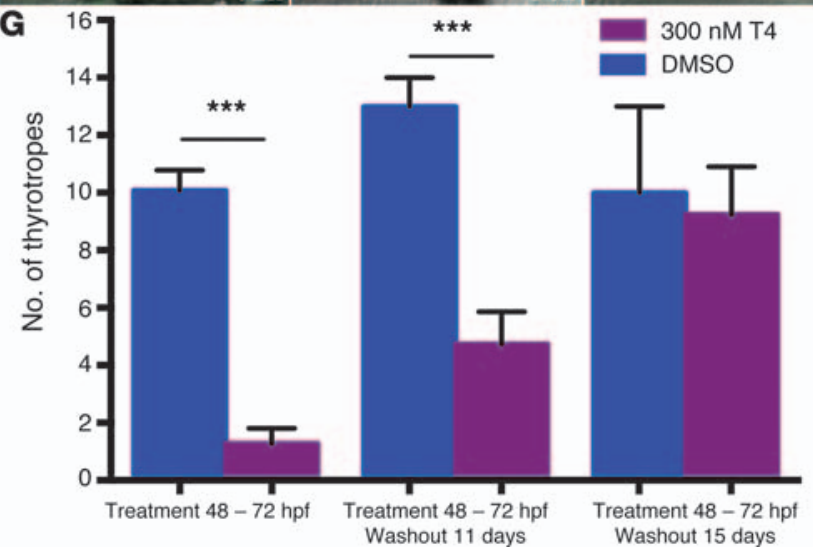

\section{Figure 4}

Lasting effects of T4 exposure on thyrotrope numbers. (A) Approximately 10 thyrotropes were present in the pituitary by $72 \mathrm{hpf}$ in DMSO-treated control embryos, as visualized by GFP fluorescence in the $T g$ (tshb:EGFP) line. (B) Example of decreased thyrotrope numbers by $72 \mathrm{hpf}$ immediately following a 24-hour exposure to $300 \mathrm{nM} \mathrm{T4}$. (C) Approximately 13 thyrotropes were present by $14 \mathrm{dpf}$ in DMSO-treated control embryos. (D) Example of a 14-dpf larva with 4 thyrotropes that was treated with $300 \mathrm{nM} \mathrm{T4}$ from 48 to $72 \mathrm{hpf}$, followed by an 11-day washout period. (E) Approximately 10 thyrotropes were present in the pituitary by $18 \mathrm{dpf}$ in DMSO-treated control embryos. (F) Example of a larva with normal thyrotrope numbers that was treated with $300 \mathrm{nM} \mathrm{T4}$ from 48 to $72 \mathrm{hpf}$, followed by a 15-day washout period. (G) Graph showing thyrotrope numbers, with a minimum of 20 embryos scored for each treatment. ${ }^{* *} P<0.001$. (A-F) Ventral views of pituitary in the left anterior forebrain. Scale bar: $25 \mu \mathrm{m}$. developing zebrafish pituitary. Hyperthyroid conditions during early pituitary development led to thyrotrope cell death, defining a critical period that precedes the onset of negative feedback of $\mathrm{TH}$ on thyrotrope tshb expression. Given the evolutionary conservation of hormone systems across vertebrate species (12-14), our studies provide an insight into early HPT axis development and offer a possible mechanism for both the immediate and extended thyroid axis dysfunction observed in rodent studies as well as the clinical observations in infants born to hyperthyroxinemic mothers.

\section{Methods}

Transgenesis and zebrafish lines. The tshb:EGFP transgene was constructed using MultiSite Gateway technology (Invitrogen) and zebrafish gateway cloning kits supplied by the Lawson and Chien labs $(35,36)$. A 3,657-bp fragment of the tshb promoter region starting $2 \mathrm{~kb}$ upstream of the translation start site and including the first intron was amplified by PCR using Tsh $\beta$.SalI.Fw (ATGCTCTACCGTCGACGCAGAAAGACTTGAATTAACTCCAC) and Tsh $\beta . S a c I I . R v$ (ATGCTCTACCCCGCGGGATAGGTGGCAGTGTATGAGGATG) primers. The amplicon was cut and ligated into the SalI/ SacII site of P5E-MCS to generate a P5E-tshb construct. A two-fragment LR recombination reaction was performed using the $\mathrm{p} 5 \mathrm{E}-\mathrm{Tsh} \beta$, pME-EGFP, and pTolDestR4-R2pA fragments to make the pEXTsh $\beta$ :EGFP construct.

To generate transgenic fish, $25 \mathrm{pg}$ of tshb:EGFP plasmid and $25 \mathrm{pg}$ of Tol2 transposase-encoding RNA was injected into wild-type zebrafish embryos at the 1- to 2-cell stage. Mosaic fish were raised to adulthood and crossed to wild-type fish to identify nonmosaic founders carrying the transgene. Two founders were identified. One line showed inappropriate GFP expression in the otic vesicle, while the second line showed appropriate expression only in the pituitary and previously reported expression in the pineal gland (37). This line was used for all subsequent analysis and has been registered at zfin.org as $\operatorname{Tg}(t \operatorname{shb}: E G F P)^{u m z 29}$. The wild-type strain used is a cross between Tü and TL strains. Zebrafish were maintained and embryos staged as described previously (38).

TH treatments. Treatments with levothyroxin (T4) and triiodothyronine (T3) (Sigma-Aldrich) were done in 12-well plates with 15 embryos per well. We took into consideration that $10 \mathrm{nM}$ T4 has been shown to rescue larvae after internal T4 production has been disrupted (39). A preliminary doseresponse experiment revealed a mild response following $30 \mathrm{nM}$ T4 treatments ( 3 times the estimated physiological concentrations), with no effect below $30 \mathrm{nM}$. A working solution of $10 \mu \mathrm{M} \mathrm{T} 4$ or T3 was freshly prepared once a week from $10 \mathrm{mM} \mathrm{T} 4$ stock in 100\% DMSO (Toronto Chemicals) or $10 \mathrm{mM} \mathrm{T} 3$ stock in $100 \% \mathrm{EtOH}$ and was diluted in $1 \mathrm{ml}$ embryo-rearing medium (ERM) (38) to the appropriate final concentrations $(30 \mathrm{nM}$, $100 \mathrm{nM}$, and $300 \mathrm{nM}$ for T4 and $10 \mathrm{nM}, 50 \mathrm{nM}$, and $100 \mathrm{nM}$ for T3 exposure). Control embryos were treated with the DMSO or EtOH carrier. We used $\mathrm{T} 4$ as the $\mathrm{TH}$ of choice because it is a more physiologically relevant TH form due to its abundance of zebrafish yolk (17) and longer half-life compared with T3. During TH exposure, embryos were kept in the dark at $28.5^{\circ} \mathrm{C}$ and fixed in $4 \%$ paraformaldehyde at the appropriate age for assay. To determine the long-lasting effects of T4, wild-type embryos were treated with $\mathrm{T} 4$ for 24 hours, then the embryos were washed twice in ERM, transferred to fresh ERM, and maintained for the indicated washout period. 

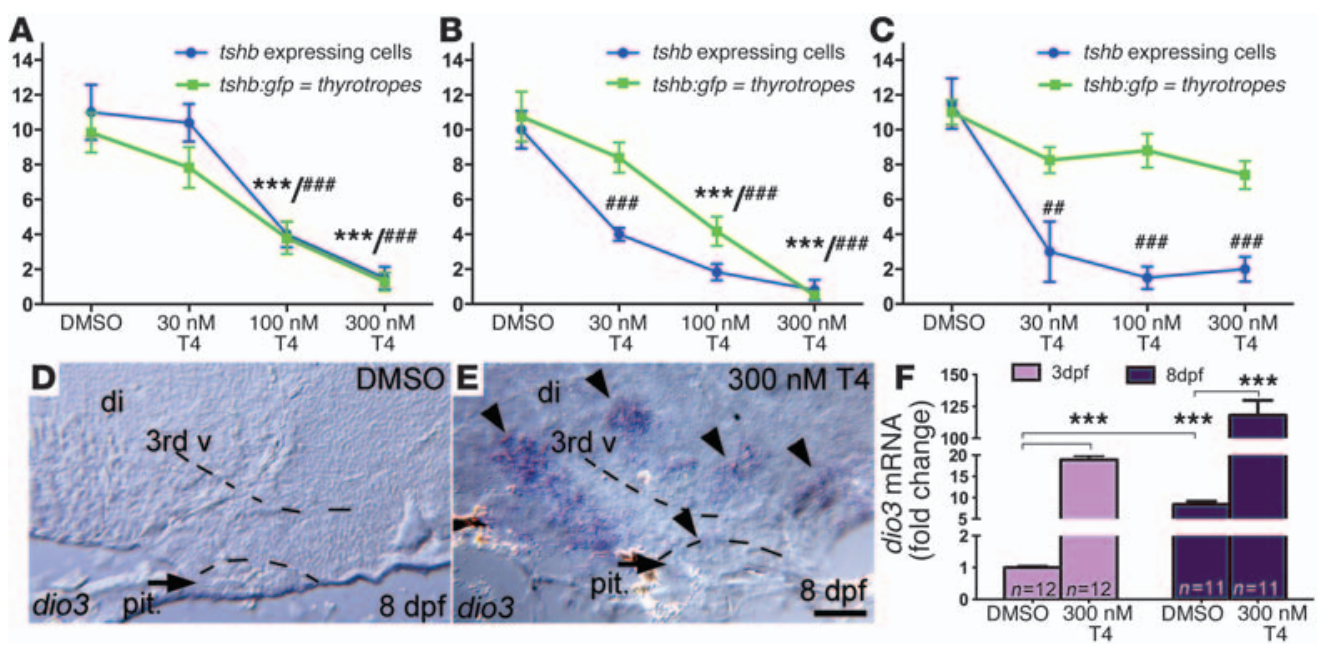

\section{Figure 5}

Onset of tshb feedback regulation. (A-C) Graphs comparing the number of tshb-expressing cells detected by ISH (blue) with the numbers of GFP-expressing thyrotropes (green) quantified in Tg(tshb:EGFP) embryos. Cells were counted following a 24-hour exposure to 30,100, or 300 nM T4 (or DMSO carrier) starting $2 \mathrm{dpf}(\mathbf{A}), 4 \mathrm{dpf}(\mathbf{B})$, or $7 \mathrm{dpf}(\mathbf{C})$. (A) Exposure to $30 \mathrm{nM} \mathrm{T} 4$ from 2 to 3 dpf had no significant effect on tshb gene expression or thyrotrope numbers, while 100- and 300-nM T4 treatments led to a loss of both tshb-and GFP-expressing cells, consistent with cell death. (B) 30-nM T4 treatments from 4 to $5 \mathrm{dpf}$ led to an approximately $50 \%$ reduction in tshb-expressing cells, with no significant change in GFP-expressing thyrotropes. Exposure to $100 \mathrm{nM}$ and $300 \mathrm{nM} \mathrm{T4}$ led to similar reductions in both tshb-and GFP-expressing cells, consistent with thyrotrope cell death. (C) 30-, 100-, and 300-nM T4 treatments from 6 to $7 \mathrm{dpf}$ did not affect the number of GFP-expressing thyrotropes. In contrast, the number of tshb-expressing cells was significantly reduced, reflecting negative feedback of T4 on tshb gene expression in the thyrotropes. (D and E) Upregulation of dio3 expression following a 24-hour exposure to $300 \mathrm{nM} \mathrm{T4}$ (E) versus DMSO (D). Pituitary (pit.) is indicated by an arrow, and the areas of dio3 expression in the diencephalic (di) and third ventricular (3rd v) regions are marked by arrowheads. (F) Graph showing expression levels (fold change) of dio3 following a 24-hour exposure to T4 by 3 versus $8 \mathrm{dpf} .{ }^{\# \#} P<0.01$; ${ }^{* *}$ and ${ }^{\# \# \#} P<0.001$. Scale bars: $25 \mu \mathrm{m}$.

ISH and immunohistochemistry. Whole-mount ISH was performed as described (40) using digoxigenin- and/or fluorescence-labeled probes (Roche). The tshb in situ probe was made as previously described $(41,42)$, while the probe for dio 2 was made using PCR-generated DNA fragments that contained the T7 (antisense primer) RNA polymerase binding sites (forward: 5'-GCTTAGTGTGGCCTCCTG-3'; reverse T7: 5'-TAATACGACTCACTATAGGGACTTTCCGTAGCACTTCTCC-3'.) Whole-mount immunohistochemistry was performed as previously described (43) using purified rabbit anti-active caspase 3 antibodies (BD Pharmingen).

Microscopy and time-lapse imaging. After ISH or active caspase 3 labeling, embryos or larvae were postfixed in $4 \%$ paraformaldehyde overnight, cleared and mounted in $75 \%$ glycerol, and photographed using DIC optics on a Zeiss Axioskop. Pituitary glands were sectioned by hand using fire-sharpened tungsten wire tools as previously described (44) after ISH was complete. $\mathrm{Tg}($ tshb:EGFP) zebrafish embryos and larvae expressing GFP in thyrotropes were fixed in $4 \%$ paraformaldehyde overnight and processed as described above. All thyrotropes were counted in confocal images of whole-mounted embryos and larvae. Time-lapse microscopy was used to observe the effects of T4 on thyrotrope numbers in live $\mathrm{Tg}(t \mathrm{shb}$ :EGFP) zebrafish embryos and larvae. Live embryos were embedded in $1.2 \%$ low-melting agarose and immersed into $300 \mathrm{nM} \mathrm{T} 4$ under the glass coverslip. Images were collected every 10 minutes using a Zeiss apotome confocal microscope and Axiovision software. Single-frame images then were analyzed for changes in thyrotrope numbers.

$R T$-qPCR. Total RNA was extracted from zebrafish embryo heads (10-12 per sample) using TRIzol reagent (Invitrogen) and a Bullet Blender homogenizer (Next Advance). Total RNA was quantified using a Nanodrop spectrometer (Thermo Fisher Scientific). Total RNA (200 ng) was reverse transcribed into cDNA using a High-Capacity cDNA Reverse Transcription kit (Applied Biosystems).
The mRNA sequence of dio 3 was acquired from the PubMed gene database, and PrimerQuest was used to design the primers: dio 3 forward: 5'CGTGTCCGACAGCAACAAGATGTTCA-3'; dio 3 reverse: 5'TCTTGAAGAAGTCCAGCTTCTGGC-3'. To ensure the specificity of the primer for the target mRNA transcript, primer sequences were blasted using the NCBI's BLAST homology search. The primers were synthesized by Invitrogen. Relative levels of dio 3 mRNA were determined by RT-qPCR using the MxPro 3000P system (Stratagene). The assays were performed in a $10-\mu \mathrm{l}$ reaction containing $1 \mu \mathrm{l}$ cDNA template, $5 \mu \mathrm{l}$ of the FastStart Universal SYBR Green Master (ROX) kit (Roche Diagnostics), $400 \mathrm{nM}$ forward and reverse primers each, and nuclease-free water. The conditions for target mRNA amplification were performed as follows: 1 cycle at $95^{\circ} \mathrm{C}$ for 15 minutes; 40 cycles each at $94^{\circ} \mathrm{C}$ for 15 seconds, $58^{\circ} \mathrm{C}$ for 45 seconds, $72^{\circ} \mathrm{C}$ for 30 seconds, and 1 cycle at $95^{\circ} \mathrm{C}$ for 1 minute, $55^{\circ} \mathrm{C}$ for 30 seconds, and $95^{\circ} \mathrm{C}$ for 30 seconds. All values were normalized to the amplification of efla mRNA (45), which was performed in parallel wells for each treatment, followed by melting-curve analysis with single-peak verification. RT-qPCR was performed in duplicate wells for each treatment. RT-qPCR data were analyzed using the $\Delta \Delta \mathrm{Ct}$ method, and the results were evaluated using 1-way ANOVA followed by a Bonferroni's $t$ test. A Grubb's test was used to identify statistical outliers in all data; the identified outliers were omitted from the final analysis, but their omission did not alter the overall results.

Statistics. Statistical significance of changes in cell numbers between groups was determined by 1-way ANOVA, followed by Tukey's multiple comparison test or a Student's $t$ test. Statistical analysis was performed using GraphPad Prism 5 (GraphPad Software). A minimum of 20 embryos were scored at each time point. Values are shown as the mean \pm SEM.

Study approval. All protocols and experiments were approved by the IACUC of the University of Massachusetts. 


\section{Acknowledgments}

The authors thank Tom Zoeller and Jason Breves for their helpful comments throughout the study and Judy Bennett for excellent fish care. Special thanks to Edward Reiter for his support of K.N. Tonyushkina as she pursued this basic research endeavor. This work was supported by the Endocrine Fellows Foundation (to K.N. Tonyushkina), the UMass/Baystate Collaborative Biomedical Research program (to K.N. Tonyushkina and R.O. Karlstrom), the Tufts University Charlton Research program (to K.N. Tonyushkina), Tufts Clinical Translational Science Institute award UL1 TR000073 (to K.N. Tonyushkina), and NIH NINDS grant NS039994 (to R.O. Karlstrom).
Received for publication March 21, 2013, and accepted in revised form September 27, 2013.

Address correspondence to: Ksenia N. Tonyushkina, Pediatric Endocrinology, 50 Wason Ave., Baystate Children's Hospital, Springfield, Massachusetts 01199, USA. Phone: 413.794.0813; Fax: 413.545.3243; E-mail: ksenia.tonyushkina@bhs.org. Or to: Rolf O. Karlstrom, Biology Department, 611 North Pleasant St., University of Massachusetts, Amherst, Massachusetts 01003, USA. Phone: 413.577.3448; Fax: 413.545.3243; E-mail: karlstrom@bio.umass.edu.
1. Patel J, Landers K, Li H, Mortimer RH, Richard K. Thyroid hormones and fetal neurological development. J Endocrinol. 2011;209(1):1-8.

2. Horn S, Heuer H. Thyroid hormone action during brain development: more questions than answers. Mol Cell Endocrinol. 2010;315(1-2):19-26.

3 . Bernal J. Thyroid hormone receptors in brain development and function. Nat Clin Pract Endocrinol Metab. 2007;3(3):249-259.

4. Bernal J. Pathophysiology of thyroid hormone deficiency during fetal development. J Pediatr Endocrinol Metab. 2005;18(suppl 1):1253-1256.

5. Grant DB, Smith I, Fuggle PW, Tokar S, Chapple J. Congenital hypothyroidism detected by neonatal screening: relationship between biochemical severity and early clinical features. Arch Dis Child. 1992; 67(1):87-90.

6. Dussault JH, Coulombe P, Laberge C, Letarte J, Guyda H, Khoury K. Preliminary report on a mass screening program for neonatal hypothyroidism. J Pediatr. 1975;86(5):670-674

7. Olney RS, Grosse SD, Vogt RF, Vogt RF Jr. Prevalence of congenital hypothyroidism - current trends and future directions: workshop summary. Pediatrics. 2010;125(suppl 2):S31-S36.

8. Fisher DAG. Disorders of the thyroid in the newborn and infant. In: Sperling MA, ed. Pediatric Endocrinology. Philadelphia, Pennsylvania, USA: Sanders-Elsevier; 2008:198-226.

9. Kempers MJ, van Tijn DA, van Trotsenburg AS, de Vijlder JJ, Wiedijk BM, Vulsma T. Central congenital hypothyroidism due to gestational hyperthyroidism: detection where prevention failed. J Clin Endocrinol Metab. 2003;88(12):5851-5857.

10. Hernandez A, Martinez ME, Fiering S, Galton VA, St Germain D. Type 3 deiodinase is critical for the maturation and function of the thyroid axis. J Clin Invest. 2006;116(2):476-484

11. Alonso M, Goodwin C, Liao X, Page D, Refetoff S, Weiss RE. Effects of maternal levels of thyroid hormone $(\mathrm{TH})$ on the hypothalamus-pituitary-thyroid set point: studies in $\mathrm{TH}$ receptor beta knockout mice. Endocrinology. 2007;148(11):5305-5312.

12. McGonnell IM, Fowkes RC. Fishing for gene function--endocrine modelling in the zebrafish. J Endocrinol. 2006;189(3):425-439.

13. Lohr H, Hammerschmidt M. Zebrafish in endocrine systems: recent advances and implications for human disease. Annu Rev Physiol. 2011;73:183-211.

14. Busby ER, Graeme JR, Sherwood NM. Endocrinology of zebrafish: a small fish with a large gene pool. In: Perry SF, Ekker M, Farrell AP, Brauner CJ, eds. Fish Physiology. Vol. 29. Philadelphia, Pennsylvania, USA: Elsevier; 2010:221-223.

15. Lam TJ. Hormones and egg/larval quality in fish. $J$ World Aquac Soc. 1994;25(1):2-12.

16. Brown SB, Adams BA, Cyr DG, Eales JG. Contaminant effects on the teleost fish thyroid. Environ Toxicol Chem. 2004;23(7):1680-1701.
17. Chang J, Wang M, Gui W, Zhao Y, Yu L, Zhu G. Changes in thyroid hormone levels during zebrafish development. Zoolog Sci. 2012;29(3):181-184.

18. Diaz ML, Becerra M, Manso MJ, Anadon R. Distribution of thyrotropin-releasing hormone (TRH) immunoreactivity in the brain of the zebrafish (Danio rerio). J Comp Neurol. 2002;450(1):45-60.

19. Devine CA, Sbrogna JL, Guner B, Osgood M, Shen MC, Karlstrom RO. A dynamic Gli code interprets Hh signals to regulate induction, patterning, and endocrine cell specification in the zebrafish pituitary. Dev Biol. 2009;326(1):143-154.

20. Nica G, Herzog W, Sonntag C, Hammerschmidt M. Zebrafish pit 1 mutants lack three pituitary cell types and develop severe dwarfism. Mol Endocrinol. 2004; 18(5):1196-1209.

21. Thisse C, et al. Spatial and temporal expression patterns of selenoprotein genes during embryogenesis in zebrafish. Gene Expr Patterns. 2003; 3(4):525-532

22. Placinta M, Shen MC, Achermann M, Karlstrom RO. A laser pointer driven microheater for precise local heating and conditional gene regulation in vivo. Microheater driven gene regulation in zebrafish. BMC Dev Biol. 2009;9:73.

23. Corish P, Tyler-Smith C. Attenuation of green fluorescent protein half-life in mammalian cells. Protein Eng. 1999;12(12):1035-1040.

24. Chowdhury I, Tharakan B, Bhat GK. Caspases an update. Comp Biochem Physiol B Biochem Mol Biol. 2008;151(1):10-27.

25. Christoffolete MA, et al. Atypical expression of type 2 iodothyronine deiodinase in thyrotrophs explains the thyroxine-mediated pituitary thyrotropin feedback mechanism. Endocrinology. 2006; 147(4):1735-1743.

26. Fliers E, Unmehopa UA, Alkemade A. Functional neuroanatomy of thyroid hormone feedback in the human hypothalamus and pituitary gland. Mol Cell Endocrinol. 2006;251(1-2):1-8.

27. Power DM, et al. Thyroid hormones in growth and development of fish. Comp Biochem Physiol C Toxicol Pharmacol. 2001;130(4):447-459.

28. de Escobar GM, Ares S, Berbel P, Obregon MJ, del Rey FE. The changing role of maternal thyroid hormone in fetal brain development. Semin Perinatol. 2008; 32(6):380-386.

29. Ishizuya-Oka A. Amphibian organ remodeling during metamorphosis: insight into thyroid hormone-induced apoptosis. Dev Growth Differ. 2011; 53(2):202-212

30. Azizi F, Vagenakis AG, Bollinger J, Reichlin S, Braverman LE, Ingbar SH. Persistent abnormalities in pituitary function following neonatal thyrotoxicosis in the rat. Endocrinology. 1974;94(6):1681-1688.

31. Higuchi R, et al. Central hypothyroidism in infants who were born to mothers with thyrotoxicosis before 32 weeks' gestation: 3 cases. Pediatrics. 2005; 115(5):e623-e625.
32. Parichy DM, Elizondo MR, Mills MG, Gordon TN, Engeszer RE. Normal table of postembryonic zebrafish development: staging by externally visible anatomy of the living fish. Dev Dyn. 2009; 238(12):2975-3015

33. Opitz R, Maquet E, Zoenen M, Dadhich R, Costagliola S. TSH receptor function is required for normal thyroid differentiation in zebrafish. Mol Endocrinol. 2011;25(9):1579-1599.

34. Kempers MJ, et al. Loss of integrity of thyroid morphology and function in children born to mothers with inadequately treated Graves' disease. J Clin Endocrinol Metab. 2007;92(8):2984-2991.

35. Villefranc JA, Amigo J, Lawson ND. Gateway compatible vectors for analysis of gene function in the zebrafish. Dev Dyn. 2007;236(11):3077-3087.

36. Kwan KM, et al. The Tol2kit: a multisite gateway-based construction kit for Tol2 transposon transgenesis constructs. Dev Dyn. 2007; 236(11):3088-3099.

37. Ji C, Jin X, He J, Yin Z. Use of TSHbeta:EGFP transgenic zebrafish as a rapid in vivo model for assessing thyroid-disrupting chemicals. Toxicol Appl Pharmacol. 2012;262(2):149-155.

38. Kimmel CB, Ballard WW, Kimmel SR, Ullmann B, Schilling TF. Stages of embryonic development of the zebrafish. Dev Dyn. 1995;203(3):253-310.

39. Liu YW, Chan WK. Thyroid hormones are important for embryonic to larval transitory phase in zebrafish. Differentiation. 2002;70(1):36-45.

40. Karlstrom RO, Talbot WS, Schier AF. Comparative synteny cloning of zebrafish you-too: mutations in the Hedgehog target gli2 affect ventral forebrain patterning. Genes Dev. 1999;13(4):388-393.

41. Concordet JP, et al. Spatial regulation of a zebrafish patched homologue reflects the roles of sonic hedgehog and protein kinase A in neural tube and somite patterning. Development. 1996;122(9):2835-2846.

42. Herzog W, Sonntag C, von der Hardt S, Roehl $\mathrm{HH}$, Varga ZM, Hammerschmidt M. Fgf3 signaling from the ventral diencephalon is required for early specification and subsequent survival of the zebrafish adenohypophysis. Development. 2004; 131(15):3681-3692.

43. de Soysa TY, et al. Macondo crude oil from the Deepwater Horizon oil spill disrupts specific developmental processes during zebrafish embryogenesis. BMC Biol. 2012;10:40.

44. Guner B, Karlstrom RO. Cloning of zebrafish nkx6.2 and a comprehensive analysis of the conserved transcriptional response to Hedgehog/Gli signaling in the zebrafish neural tube. Gene Expr Patterns. 2007;7(5):596-605.

45. Walpita CN, Van der Geyten S, Rurangwa E, Darras VM. The effect of 3,5,3'-triiodothyronine supplementation on zebrafish (Danio rerio) embryonic development and expression of iodothyronine deiodinases and thyroid hormone receptors. Gen Comp Endocrinol. 2007;152(2-3):206-214. 